\title{
Soil Microbial Functional Diversity Responses to Different Vegetation Types in the Heilongjiang Zhongyangzhan Black-billed Capercaillie Nature Reserve
}

\author{
Xiaohong Weng \\ Heilongjiang University \\ Jiayi Li \\ Heilongjiang University \\ xin sui ( $\nabla$ xinsui_cool@126.com ) \\ Heilongjiang University \\ Mengsha Li \\ Heilongjiang University \\ Weiping Yin \\ Heilongjiang University \\ Weichao Ma \\ Heilongjiang University \\ Libin Yang \\ Heilongjiang University \\ Liqiang $\mathrm{Mu}$ \\ Heilongjiang University
}

\section{Research Article}

Keywords: Soil microorganisms, vegetation types, carbon source utilization patterns, Biolog microplate technology

Posted Date: April 16th, 2021

DOI: https://doi.org/10.21203/rs.3.rs-388852/v1

License: (c) (i) This work is licensed under a Creative Commons Attribution 4.0 International License. Read Full License 
Version of Record: A version of this preprint was published at Annals of Microbiology on July 9th, 2021. See the published version at https://doi.org/10.1186/s13213-021-01638-4. 


\section{Abstract}

Purpose: The soil microbial community is an important bioactive component of terrestrial ecosystems. Its structural and functional diversity directly affects carbon and nitrogen processes. This study aimed to investigate the variations in the functional diversity of soil microbial communities in forests with different types of vegetation.

Methods: We selected three typical vegetation types, larch (LG), black birch (BD), and larch and black birch mixed (LGBD) forests, located in the Heilongjiang Zhongyangzhan Black-billed Capercaillie Nature Reserve. The Biolog-Eco microplate technology was selected to perform these analyses.

Result: Our results showed clear differences between microorganisms in the three typical forests. The average well-colour development (AWCD) change rate gradually increased with incubation time. The BD type had the highest AWCD value, followed by LGBD; the LG forest type had the lowest value. The difference in the soil microbial alpha diversity index between BD and LG was significant. A principal component analysis showed that PC1 and PC2 respectively explained $62.77 \%$ and $13.3 \%$ of the variance observed. The differences in the soil microbial carbon-source utilization patterns under different vegetation types were mainly caused by esters and carbohydrates. Redundancy analysis showed that soil microbial functional diversity was strongly affected by soil physicochemistrical properties (e.g. organic carbon, total nitrogen, and $\mathrm{pH}$ ).

Conclusion: These results provide a reference for further exploring the relationship between forest communities and soil microbes during the process of forest succession.

\section{Background}

As pioneer species and important active components in the process of biological evolution, microorganisms are widely involved in soil biological and biochemical processes (Gao et al., 2015). Soil microorganisms are an important driving factor for material conversion and nutrient cycling. They play key roles in ecosystem functional maintenance and biogeochemical cycle processes, directly or indirectly promote plant growth, influence vegetation succession processes, and can significantly impact ecosystem development (Fierer et al., 2006; Zhang et al., 2012; Bellingham et al., 2002). Geological conditions, vegetation composition, and other factors also have a feedback effect on soil microbial activity and diversity (Han et al., 2015; Kennedy et al., 2005). Changes in aboveground vegetation composition influence soil microbial biomass, activity, community structure, and function (Hua et al., 2004; Sarah et al., 2010; Yoshitake et al., 2013; Glanville et al., 2012). Changes in soil microbial community and function also impact aboveground plant composition and diversity. Therefore, soil microorganisms are of great significance to the forest ecosystem and have critical roles in vegetation renewal and succession processes. The study of how vegetation impacts soil microbes is an increasingly popular topic for ecologists, especially research regarding the functional mechanisms of ecosystems. 
Current research mainly focuses on studying the metabolic diversity of soil microbial communities in different soil types, climatic conditions, human disturbances, and different vegetation rhizosphere environments. The activity and the function of soil microbial communities can be estimated by determining the number of bacteria and type of metabolic diversity present. The number of bacteria is a key factor to study microbial community size. Biolog-Eco is a simple and fast method to study the structure and functional diversity of soil microbial communities with high sensitivity and resolution (Garland, 1997; Zheng et al., 2004). It can be used to obtain microbial information that reflects the population's metabolic characteristics and functions by testing the single energy carbon utilization abilities of the microorganisms. The phospholipid fatty acid (PLFA) method and the various molecular biological traditional methods available do not reflect the soil microbial function (Bossio \& Scow, 1995; Buyer \& Drinkwater, 1997; Yang et al., 2002; Xi et al., 2005). Conversely, the Biolog-Eco method can reflect information about the overall activity and metabolic function of microbial communities. The Biolog-Eco method has been utilized to study the impact of land use and human disturbance on soil microorganisms under environmental pollution stress. Although many studies have focused on soil microbes, few addressed the functional diversity of soil microorganisms in different forest types.

The Heilongjiang Zhongyangzhan Black-billed Capercaillie Nature Reserve is located in the transitional zone of the large Xing'an Mountains and small Xing'an Mountains. The forest types are rich, and there are obvious staggered patches. The main forest types are larch (Larix gmelinii), white birch (Betula platyphylla), black birch (Betula dahurica), and Mongolian oak (Quercus mongolica). Nevertheless, how the various types of vegetation affect soil microbial functional diversity remains unclear. In this study, Biolog-Eco microplate technology was used to investigate the variation in soil microbial functional diversity in three typical vegetation types (larch, LG; black birch, BD; and larch and black birch mixed, LGBD) in the Heilongjiang Zhongyangzhan Black-billed Capercaillie Nature Reserve. The aim was to explore the impact of forest vegetation changes and diversity on soil microbial community function and provide a basis to study the relationship between soil microbes and environmental factors in the Heilongjiang Zhongyangzhan Black-billed Grouse National Nature Reserve.

\section{Results}

\section{Soil physical-chemical properties}

The physical and chemical properties of the three different soil forest types tested are summarised in Table 1. Significant differences in soil $\mathrm{pH}$, organic carbon, total nitrogen, and carbon-to-nitrogen ratio $(P<0.05)$ were observed among the three forest types. BD forest soil had the highest $\mathrm{pH}$ value $(5.86)$ and LG forest had the lowest (4.61). BD also had the highest value of soil organic carbon $\left(60.3 \mathrm{~g} \cdot \mathrm{kg}^{-1}\right)$, while LG had the lowest $\left(49.9 \mathrm{~g} \cdot \mathrm{kg}^{-1}\right)$. The same trend was observed for total nitrogen, with BD having the highest (4.12 mg. $\left.\mathrm{kg}^{-1}\right)$, and LG the lowest (2.76 mg. $\mathrm{kg}^{-1}$ ) values. Finally, LG and BD had the highest (18.1) and lowest (14.7) soil carbon to nitrogen ratio, respectively.

Table 1. Soil chemical and physical properties. 


\begin{tabular}{ccccc}
\hline Forest type & $\mathrm{pH}$ & $\mathrm{SOC}\left(\mathrm{g} \cdot \mathrm{kg}^{-1}\right)$ & $\mathrm{TN}\left(\mathrm{mg} \cdot \mathrm{kg}^{-1}\right)$ & $\mathrm{C} / \mathrm{N}$ \\
\hline $\mathrm{BD}$ & $5.9 \pm 0.34 \mathrm{a}$ & $60.3 \pm 3.48 \mathrm{a}$ & $4.1 \pm 0.13 \mathrm{a}$ & $14.7 \pm 1.29 \mathrm{~b}$ \\
LGBD & $5.5 \pm 0.13 \mathrm{a}$ & $54.0 \pm 3.53 \mathrm{ab}$ & $3.5 \pm 0.34 \mathrm{~b}$ & $15.6 \pm 0.76 \mathrm{ab}$ \\
LG & $4.6 \pm 0.39 \mathrm{~b}$ & $49.9 \pm 3.95 \mathrm{~b}$ & $2.8 \pm 0.13 \mathrm{c}$ & $18.1 \pm 1.58 \mathrm{a}$ \\
\hline
\end{tabular}

Note: Each treatment contained three replicates. Data are expressed as the mean \pm standard error; lowercase letters indicate significant differences $(P<0.05)$. LG: Larix gmelinii; BD: Betula dahurica; and LGBD: mixed Larix gmelinii and Betula dahurica.

\section{Difference in average colour change rate of soil microorganisms}

The AWCD is used to characterise microbial communities. It is an important indicator of the soil microbial community's ability to use a single carbon source, and it reflects soil microbial activity and diversity of physiological functions (Kenarova et al., 2014; Magdalena et al., 2012). A high AWCD can lead to high activity and density of soil microorganisms; conversely, low AWCD decreases microorganism density and activity. The metabolic activity for soils of the three forest types was analysed from 24 to $240 \mathrm{~h}$. As seen in Fig. 1, the AWCD value for the three forest types increased with increasing the incubation time. LD and LGBD had a significant increasing trend within the first $24 \mathrm{~h}$, but the value strongly increased for $\mathrm{BD}$. This rapid increase in AWCD indicated that the soil microbial community could metabolise organic substrates on the Biolog-Eco microplates. The increasing trend was maintained from 24 to $144 \mathrm{~h}$ (Fig. 1). The highest AWCD value occurred at $96 \mathrm{~h}$, which indicated the soil microorganism had the highest ability to utilise carbon sources at that time point. After $96 \mathrm{~h}$, the AWCD increase deaccelerated and tended to stabilise after $216 \mathrm{~h}$ of incubation, indicating all culturable microorganisms can use the carbon source stably during the stable period (Miyake et al., 2016).

$B D$ reached the highest AWCD value among the three forest-type soil samples. The AWCD increased from 0 to 1.43 , at $216 \mathrm{~h}$, for $\mathrm{BD}$, and approximately to 1.14 for the mixed LGBD, indicating that the broad-leaved BD forest had the highest soil microbial activity. However, the AWCD of LG tended to stabilize around 1.12 , indicating that the coniferous forest had the lowest soil microbial activity. In summary, different vegetation types caused differences in the microbial AWCD utilization rate, with BD having the highest value, followed by LGBD, and with LG having the lowest AWCD.

\section{Changes in soil microbial metabolic diversity}

In this study, the Biolog-Eco board had different types of carbon sources that were used to treat the soil microbial communities. Therefore, the alpha diversity could be used as an indicator of the soil microbial communities' diversity in various perspectives. The absorbance values of the soil microorganisms at $96 \mathrm{~h}$ were used to determine Shannon (H), Simpson (D), and McIntosh (U) values. As shown in Table 2, the diversity index reflects the impact of different plant compositions on microbial community functions. Overall, there were significant differences in the Shannon-Wiener, Simpson, and Mclntosh indexes 
between the three forest types (Table 1, $P<0.05$ ). The Shannon-Wiener index was the highest for BD, at 3.05. The McIntosh index was the highest for $L G$, at 9.28, and the lowest for $B D$, at 7.14.

Table 2 Soil microbial functional diversity of carbon utilization

\begin{tabular}{cccc}
\hline Vegetation types & Shannon-Wiener index $(H)$ & Simpson index (D) & McIntosh index (U) \\
\hline BD & $3.1 \pm 0.07 \mathrm{a}$ & $0.95 \pm 0.02 \mathrm{~b}$ & $7.1 \pm 0.00 \mathrm{~b}$ \\
LG & $2.9 \pm 0.11 \mathrm{a}$ & $0.96 \pm 0.01 \mathrm{a}$ & $9.3 \pm 0.00 \mathrm{a}$ \\
LGBD & $2.3 \pm 0.26 \mathrm{~b}$ & $0.95 \pm 0.01 \mathrm{~b}$ & $8.3 \pm 0.00 \mathrm{ab}$ \\
\hline
\end{tabular}

Note: Each treatment contained three replicates. Data are expressed as the mean \pm standard error; lowercase letters indicate significant differences $(P<0.05)$. LG: Larix gmelinii; BD: Betula dahurica; and LGBD: mixed Larix gmelinii and Betula dahurica.

\section{Carbon source metabolization response rates of microbial communities from various vegetation types}

Based on physiological and biochemical characteristics, the 31 carbon substrates of the Biolog-Eco microplate were categorized into 6 types: carbohydrates, amino acids, esters, alcohols, amines, and acids (Cao et al., 2018) (Table 3). The microbial metabolic fingerprint represents the ability of microorganisms to utilise a wide variety of carbon sources. The utilization capacity of the 6 carbon sources varied with the microbial communities. As seen in Fig. 2, for BD, there was 1 type of carbon source with an AWCD higher than 2.0 in the metabolic fingerprint, L-asparagine (2.2242). Six kinds of sources were observed in LG: glycogen, D-cellobiose, Tween 40, D-mannitol, phenylethylamine, N-acetyl-D-glucosamine, and Dcellobiose, which had a highest AWCD of 2.5686. Finally, there were 5 types in LGBD: L-arginine, Lasparagine, Tween 40, D-mannitol, $\mathrm{Y}$-hydroxybutyric acid, and L-asparagine, which had a highest AWCD of 2.7193 .

Table 3. Loading factors of the principal components of the 31 individual carbon sources 


\begin{tabular}{|c|c|c|c|c|c|}
\hline $\begin{array}{c}\text { Chemical } \\
\text { guild }\end{array}$ & $\begin{array}{c}\text { Plate } \\
\text { number }\end{array}$ & Carbon source & Chemical formula & PCA1 & PCA2 \\
\hline \multirow[t]{9}{*}{ Carbohydrate } & B2 & D-Xylose & $\mathrm{C}_{5} \mathrm{H}_{10} \mathrm{O}_{5}$ & 0.999 & 0.040 \\
\hline & H1 & $\alpha$-D-Lactose & $\mathrm{C}_{12} \mathrm{H}_{22} \mathrm{O}_{11}$ & 0.826 & 0.563 \\
\hline & A2 & $\beta$-Methyl-D- & $\mathrm{C}_{7} \mathrm{H}_{14} \mathrm{O}_{6}$ & -0.435 & 0.900 \\
\hline & & Glucoside & & & \\
\hline & $\mathrm{G} 2$ & $\alpha$-D-Glucose-1- & $\mathrm{C}_{6} \mathrm{H}_{13} \mathrm{O}_{10} \mathrm{p}$ & 0.999 & -0.041 \\
\hline & & Phosphate & & & \\
\hline & E1 & $\alpha$-Cyclodextrin & $\mathrm{C}_{36} \mathrm{H}_{60} \mathrm{O}_{30} . \mathrm{H}_{2} \mathrm{O}$ & 0.997 & -0.079 \\
\hline & $\mathrm{F} 1$ & Glycogen & $\left(\mathrm{C}_{6} \mathrm{H}_{10} \mathrm{O}_{5}\right)_{\mathrm{n}}$ & -0.452 & 0.892 \\
\hline & G1 & D-Cellobiose & $\mathrm{C}_{12} \mathrm{H}_{22} \mathrm{O}_{11}$ & 0.966 & -0.257 \\
\hline \multirow[t]{7}{*}{ Amino acids } & A4 & L-Arginine & $\mathrm{C}_{6} \mathrm{H}_{14} \mathrm{~N}_{4} \mathrm{O}_{2}$ & 0.986 & 0.168 \\
\hline & B4 & L-Asparagine & $\mathrm{C}_{27} \mathrm{H}_{18} \mathrm{C}_{13} \mathrm{~N}_{3} \mathrm{O}$ & 0.992 & 0.128 \\
\hline & $\mathrm{C} 4$ & L-Phenylalanine & $\mathrm{C}_{9} \mathrm{H}_{11} \mathrm{NO}_{2}$ & 0.693 & 0.721 \\
\hline & $\mathrm{D} 4$ & L-Serine & $\mathrm{HOCH}_{2} \mathrm{CH}\left(\mathrm{NH}_{2}\right) \mathrm{CO}_{2} \mathrm{H}$ & 0.986 & 0.169 \\
\hline & E4 & L-Threonine & $\mathrm{C}_{4} \mathrm{H}_{9} \mathrm{NO}_{3}$ & 0.984 & 0.176 \\
\hline & $\mathrm{F} 4$ & Glycyl-L-Glutamic & $\mathrm{C}_{7} \mathrm{H}_{12} \mathrm{~N}_{2} \mathrm{O}_{5}$ & 0.867 & 0.498 \\
\hline & & Acid & & & \\
\hline \multirow[t]{6}{*}{ Esters } & B1 & Pyruvic Acid & $\mathrm{C}_{4} \mathrm{H}_{6} \mathrm{O}_{3}$ & 0.250 & 0.968 \\
\hline & & Methyl Ester & & & \\
\hline & C1 & Tween 40 & $\mathrm{C}_{22} \mathrm{H}_{42} \mathrm{O}_{6} \cdot\left(\mathrm{C}_{2} \mathrm{H}_{4} \mathrm{O}\right)_{\mathrm{n}}$ & -0.265 & 0.964 \\
\hline & D1 & Tween 80 & $\mathrm{C}_{24} \mathrm{H}_{44} \mathrm{O}_{6} \cdot\left(\mathrm{C}_{2} \mathrm{H}_{4} \mathrm{O}\right)_{\mathrm{n}}$ & -0.477 & 0.879 \\
\hline & A3 & D-Galacturonic & $\mathrm{C}_{6} \mathrm{H}_{10} \mathrm{O}_{6}$ & -0.220 & 0.976 \\
\hline & & Acid & & & \\
\hline \multirow[t]{5}{*}{ Alcohols } & $\mathrm{C} 2$ & i-Erythritol & $\mathrm{C}_{4} \mathrm{H}_{10} \mathrm{O}_{4}$ & 0.963 & 0.271 \\
\hline & D2 & D-Mannitol & $\mathrm{C}_{6} \mathrm{H}_{14} \mathrm{O}_{6}$ & 0.997 & -0.079 \\
\hline & $\mathrm{H} 2$ & D,L- $\alpha$-Glycerol & $\mathrm{C}_{3} \mathrm{H}_{9} \mathrm{O}_{6} \mathrm{P}$ & 0.997 & -0.079 \\
\hline & & Phosphate & & & \\
\hline & & Page & & & \\
\hline
\end{tabular}




\begin{tabular}{|c|c|c|c|c|c|}
\hline \multirow[t]{3}{*}{ Amine } & G4 & L-Phenylalanine & $\mathrm{C}_{8} \mathrm{H}_{11} \mathrm{~N}: \mathrm{C}_{6} \mathrm{H}_{5} \mathrm{CH}_{2} \mathrm{CH}_{2} \mathrm{NH}_{2}$ & 0.693 & 0.721 \\
\hline & $\mathrm{H} 4$ & Putrescine & $\mathrm{C}_{4} \mathrm{H}_{12} \mathrm{~N}_{2}$ & 0.992 & 0.130 \\
\hline & E2 & N-Acetyl-D- & $\mathrm{C}_{8} \mathrm{H}_{15} \mathrm{NO}_{6}$ & 0.449 & 0.894 \\
\hline & & Glucosamine & & & \\
\hline \multirow[t]{14}{*}{ Acids } & B3 & D-galacturonic & $\mathrm{C}_{6} \mathrm{H}_{10} \mathrm{O}_{7}$ & 0.998 & 0.057 \\
\hline & & acid & & & \\
\hline & $\mathrm{F} 2$ & D-glucosaminic & $\mathrm{C}_{6} \mathrm{H}_{13} \mathrm{NO}_{6}$ & -0.512 & 0.859 \\
\hline & & acid & & & \\
\hline & $\mathrm{C} 3$ & 2-Hydroxy Benzoic & C7H6O3 & 1.000 & -0.008 \\
\hline & & Acid & & & \\
\hline & D3 & 4-Hydroxy Benzoic & $\mathrm{C}_{7} \mathrm{H}_{6} \mathrm{O}_{3}$ & -0.489 & 0.872 \\
\hline & & Acid & & & \\
\hline & E3 & $\gamma-$ & $\mathrm{C}_{4} \mathrm{H}_{8} \mathrm{O}_{3}$ & 1.000 & -0.004 \\
\hline & & Hydroxybutyric & & & \\
\hline & & Acid & & & \\
\hline & F3 & Itaconic Acid & $\mathrm{C}_{5} \mathrm{H}_{6} \mathrm{O}_{4}$ & 1.000 & 0.021 \\
\hline & G3 & $\alpha-K e t o b u t y r i c ~ A c i d ~$ & $\mathrm{C}_{4} \mathrm{H}_{6} \mathrm{O}_{3}$ & 0.997 & 0.071 \\
\hline & H3 & D-Malic Acid & $\mathrm{C}_{4} \mathrm{H}_{6} \mathrm{O}_{5}$ & 0.996 & -0.088 \\
\hline
\end{tabular}

Heatmap analysis visually showed the difference in the metabolic rates of different carbon sources for the microbial communities in all soil samples (Fig. 3), highlighting differences for the various vegetation types. The heat map results were separated into three categories (Fig. 4). In group I, the AWCD values of D, L-a-glycerol phosphate, glycogen, a-cyclodextrin, L-phenylalanine, D-xylose, and D-cellobiose were

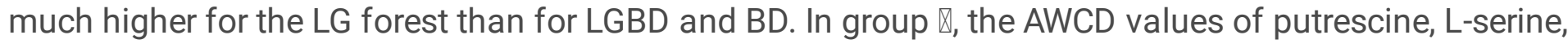
Tween 80, $\mathrm{Y}$-hydroxybutyric acid, L-arginine, L-asparagine, D-galacturonic acid, 4-hydroxy benzoic acid,

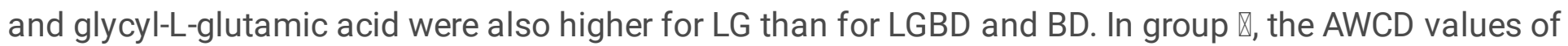
L-phenylalanine, L-threonine, a-ketobutyric acid, and pyruvic acid methyl ester, and of i-erythritol and itaconic acid were not significantly different between forest types. This indicated that LG had higher density and enhanced soil microorganism activity than the BD forest and LGBD forests.

\section{PCA of carbon source metabolization}

Principal component analyses (PCA) were performed to examine the carbon source metabolism of the microbial communities from the three forest types (Sui et al., 2016). For the Biolog-Eco, the load value of 
the 31 carbon sources in the main component increased with the impact of the carbon source on the main component. As seen in Table 3, 24 carbon sources constituted the first main subdivision (PC1). These included 5 carbohydrates, 6 amino acids, 3 alcohols, 2 amines, and 8 acids, of which 2-hydroxy benzoic acid, $y$-hydroxybutyric acid, and itaconic acid were the most relevant carbon sources to PC1 (1.000). Therefore, acids had a major effect on PC1. In addition, 14 kinds of carbon sources constituted the secondary major subdivision (PC2). These included 3 carbohydrate types, 2 amino acid types, 4 ester types, 2 amines types, and 3 acid types, among which D-galacturonic acid was the most important carbon source. Therefore, carbohydrates, esters, and acids had important effects on PC2.

A PCA analysis was performed to find the variance of carbon utilization of soil microorganisms in different samples (Felipe-Sotelo et al., 2008; Illian et al., 2009). Multivariate vectors were converted into two unrelated principal component vectors. The variance contribution rate of principal component 1 was $62.77 \%$, and the contribution rate of principal component 2 was $13.38 \%$ (Fig. 4). After a dimensionality reduction, the location images of the points in the main carrier space of the carbon source directly reflected the differences in soil carbon utilization ability of microorganisms in soils from different forest types (Kim et al., 2017). This explained the utilization of various carbon source. The PCA results confirmed the coordinate mapping of the various processing methods for the two major components, showing that the distance between the three sub-sampling points of various processing was small and separated from other components. PCA of carbon source metabolism of microbial communities indicated that the soil microbial community function in $L G$ coniferous forests tended to be far from that of LGBD and BD broad-leaved forests, especially along the PCA1 axis (Fig. 4). The analyses of microbial communities showed that soil microbial carbon source metabolic capacity significantly differed with the vegetation types, especially in the two types of esters and carbohydrates.

\section{Differences and factors influencing soil microbial carbon source utilisation patterns in different vegetation types}

The environmental factors that affected soil microbial community activity and soil physicochemical properties were analysed through canonical correlation analyses. The two CCA axes explained $56.43 \%$ and $12.89 \%$ of the variance (Fig. 5). The first CCA axis was close to the soil organic carbon content $(r=$ $0.98039)$ and TN content $(r=0.96100)$. The second CCA axis was negatively correlated with soil pH $(r=$ $-0.4820)$ and $\mathrm{C} / \mathrm{N}(\mathrm{r}=-0.6165)$. The various vegetation types were well separated along the CCA axis (Fig. 5). The BD, LG, and LGBD forests were distanced from each other along the CCA1 axis (Fig. 5), and the sample points of the LGBD and BD forests were close to each other.

We analysed the relationship of soil physical and chemical properties and soil microbial alpha diversity (Table 4). As shown in Table 4, for the soil physical and chemical properties, the Shannon index was positively correlated with soil organic carbon $(r=0.678, P<0.05)$, and total nitrogen $(r=0.828, P<0.01)$ was extremely and positively related with $\mathrm{C} / \mathrm{N}(\mathrm{r}=-0.758, P<0.01)$. 
Table 4. Correlation coefficients between soil nutrients and soil microbial functional diversity.

\begin{tabular}{ccccc}
\hline & $\mathrm{pH}$ & $\mathrm{SOC}$ & $\mathrm{TN}$ & $\mathrm{C} / \mathrm{N}$ \\
\hline AWCD & -0.65 & -0.51 & -0.46 & 0.18 \\
$\mathrm{H}$ & -0.61 & $\mathbf{0 . 6 8}^{*}$ & $\mathbf{0 . 8 3}$ & $\boldsymbol{- 0 . 7 6 ^ { * }}$ \\
$\mathrm{D}$ & -0.50 & -0.56 & -0.41 & 0.12 \\
$\mathrm{U}$ & -0.43 & -0.64 & -0.40 & 0.03 \\
\hline
\end{tabular}

Note: ${ }^{* *}$ correlation significant at the 0.01 level (two-tailed); ${ }^{*}$ correlation significant at the 0.05 level (two-tailed)

\section{Discussion}

\section{Different vegetation types correlate with different soil physicochemical characteristics}

Climate, vegetation, and soil physical and chemical properties are important environmental factors related to soil microbial characteristics. In this study, the three forest types investigated (Larix gmelinii coniferous forest, LG; Betula dahurica broad-leaved forest, BD; and Betula dahurica and Larix gmelinii mixed forest, LGBD) had the same soil texture and the same climate. Therefore, differences in soil physicochemical properties and microbial alpha diversity can significantly affect the quality and quantity of organic carbon in the different vegetation types. In this study, the soil pH ranged from 4.61 to 5.86 . The soil $\mathrm{pH}$ was the lowest for $\mathrm{LG}$ and the highest for BD. The differences may come from the chemical composition of different litters (Waid, 1999). Litter quality and total nitrogen content were lower in LG than in other forest types, whereas the $\mathrm{C} / \mathrm{N}$, lignin content, and lignin/ $\mathrm{N}$ were higher in $\mathrm{LG}$. Therefore, the decomposition rate of the LG forest litter and the release rate of plant nutrients should be reduced (Gao et al., 2016). This may be the cause for the low soil pH in the LG forest.

In addition, we found that the total carbon and total nitrogen content of the BD ecosystem were higher than in LG and LGBD forests (Table 2). Our results are consistent with previously published findings that broad-leaved forests have higher soil organic matter and nitrogen content than coniferous forests (Ding et al., 2017). Other studies have also found that the values for these soil physicochemistrical properties were lower in coniferous forests than in broad-leaved forests (Gao et al., 2015; Geng et al., 2013). The high content of soil organic carbon and total nitrogen in broad-leaved forests may be due to the continuous input of litter, root effects, and turnover of soil nutrients (Ge et al., 2012). Litter in the larch forests contains high levels of difficult-to-decompose lignin and organic acids (Ge et al., 2012). Research also demonstrated that the soil carbon-to-nitrogen ratio in various forest types can drastically change the structure and function of soil microbes (Jiang et al., 2014). In this study, the soil C/N ratio was higher in 
LG than in the BD forest, which contradicts previously published results (Yoshimura et al., 2008; Stéphane et al., 2008). This may be because the $L G$ forest in this study has a single community type and a single type of litter. The chemical composition of the main litter has a significant impact on soil chemical properties (Fu et al., 2019). A large number of previous studies have shown that the composition ratio of aboveground tree species significantly impacts the soil, which is consistent with the results of this study (Chodak \& Niklinska, 2010; Huang et al., 2012; Wu et al., 2013).

\section{Different vegetation types contribute to different soil microbial functional diversities}

In this study, the soil alpha diversity was significantly different in the three forest types (Table 4). These results indicate that the type of forest vegetation correlates with soil microbial functional diversity. The metabolic functional diversity of the soil microbial community is reflected by the functional diversity index (Sui et al., 2016). Our research demonstrated that the soil microbial functional diversity index was higher in BD than in the LG and LGBD forests. Previous research has indicated that the Shannon-Wiener index, Simpson index, and Mclntosh index of soil microorganisms are higher in broad-leave than in coniferous forests (Hu et al., 2010). Other studies have shown this using different methods (Wu et al., 2013). In this study, the soil microorganisms' functional diversity was the lowest in coniferous LG forests and the highest for broad-leaf BD forests. The soil microbial Biolog-Eco functional diversity Shannon index was lower in LG than in LGBD and BD. These analyses found that the soil microbial functional diversity is correlated to the forest's dominant tree species. Indeed, various forest types impact microbial functional diversity by influencing soil physical and chemical properties (Anderson et al., 2009).

Our research found that microbial community functional activities were significantly different in the three forest types (Fig. 2, 3), which may be closely related to the soil physical and chemical characteristics (Fig. 5, Table 4). As evident in the heat map and PCA results, the beta diversity of soil microbial communities was significantly different in the three forests. It is known that regions with different vegetation types also differ in the soil microorganism composition (Ushio et al., 2010; Eilers et al., 2009). The organic carbon and total nitrogen contents were positively correlated with the Shannon index in our data, and soil $\mathrm{C} / \mathrm{N}$ was negatively correlated with the same index. These results are inconsistent with what was reported by Deng et al. (2019). Different vegetation types produce different amounts and qualities of plant litter input (Ushio et al., 2010; Zhang et al., 2006), promoting different types of microorganisms in the soil (Sariyildiz \& Anderson, 2003; Tripathi et al., 2013). Therefore, these results indicate that the difference in litter composition of each vegetation composition leads to changes in nutrient content and $\mathrm{pH}$ in the soil, affecting the structure and function of microorganisms present.

\section{Conclusions}

In this paper, we analysed the changes in metabolic activity and functional diversity of soil microbial communities in three different forest types. The results showed that different vegetation types led to significant differences in the functional diversity of soil microbial communities. The metabolic activities were significantly higher in the coniferous and broad-leaved mixed and broad-leaved forests than in the 
coniferous forest type. Additionally, the broad-leaved forests had the highest soil microbial functional diversity. Soil organic carbon and total nitrogen are the main parameters that affect the functional diversity of soil microbial communities. Therefore, forest composition can change the functional diversity of microorganisms by altering the physical and chemical properties of the soil.

Due to the limitation of carbon source types available, the Biolog-Eco method is not sufficient to completely explore the function and diversity of microorganisms. In the future, it will be necessary to combine enzyme kinetics and molecular biology approaches, especially high-throughput sequencing, in this type of research.

\section{Methods}

\section{Study area}

The experimental site is located in the Heilongjiang Zhongyangzhan Black-billed Capercaillie National Nature Reserve (Fig. 6). The reserve is located in south-western Heihe city, Heilongjiang Province, and this reserve is the transition zone between the south-western mountains of Xiaoxing'anling and the Songnen Plain. The geographical location is $126^{\circ} 00^{\prime}-126^{\circ} 45^{\prime} \mathrm{E}, 48^{\circ} 30^{\prime}-48^{\circ} 50^{\prime} \mathrm{N}$, and the total area is $988.6 \mathrm{~km}^{2}$. This area is located at a temperate continental monsoon climate zone, with severe cold in winter and cool and short summers. The annual average temperature is $-0.5^{\circ} \mathrm{C}$, the frost-free period is $121 \mathrm{~d}$, the annual average rainfall is $476.33 \mathrm{~mm}$, and the average relative humidity for many years has been $69.2 \%$. The different vegetation types are randomly distributed and are affected by the surrounding environment. The plant communities are in different succession stages. The research site (nature reserve) is a typical alpine forest ecosystem with forests, shrubs, wetlands, and meadows. Forests include coniferous and broadleaved mixed forests, coniferous forests, and broad-leaved forests. Wetlands include forest swamps, shrub swamps and herb marshes, and swampy meadows and other wetland types. Most of the nature reserve is covered by forests, with a forest coverage rate of $82.4 \%$ (Yin et al., 2019).

The main plants present are Larix gmelinii, Tilia amurensis, Chosenia arbutifolia, Betula platyphylla, Betula dahurica, Quercus mongolica, Populus davidiana, Prunus padus, Salix raddeana, and Alnus mandshurica.

\section{Research methods}

\section{Plot setting and sample collection}

In July 2019, plot selection and sample collection were conducted in a day with sunshine and a temperature of $20^{\circ} \mathrm{C}$. Three typical vegetation types, Larix gmelinii (coniferous larch forest, LG), Betula dahurica (broad-leaved black birch forest, BD), and Betula dahurica and Larix gmelinii mixed forest (LGBD) were selected in larger Xing'an. Three plots were used for each vegetation type. The area of each plot was approximately $400 \mathrm{~m}^{2}$. Three small plots of $10 \mathrm{~m} \times 10 \mathrm{~m}$ were arranged at the four corners and the middle of each plot to collect soil. The sampling method was a 5-point sampling method, collecting 
0-20 cm surface soil, mixed into 1 soil sample, with 5 samples per community sample. After removing plant debris, the samples were passed through a $2 \mathrm{~mm}$ sieve and placed in sterile bags. The samples used for the determination of soil microbial diversity and other indicators were placed in an incubator with an ice bag and kept in the laboratory at $4^{\circ} \mathrm{C}$. Another part of the sample was dried naturally, and soil nutrients and other indicators were measured after sieving.

\section{Determination of soil physical and chemical factors}

Soil pH was analysed by the water extraction potential method (water-soil ratio 2.5: 1). Soil organic carbon (soil organic carbon, $\mathrm{SOC}$ ) and total nitrogen (total nitrogen, $\mathrm{TN}$ ) were determined with an elemental analyser (Arvato EA3000).

\section{Determination of the functional diversity of soil microbial community}

The Biolog GN microplate has a total of 96 holes. The first hole works as a control without a carbon source, and the others contain a carbon source and redox dye tetrazolium blue. Microorganisms use carbon sources to breathe changing the redox potential and reducing tetrazoles (TV) from colourless to purple. Ten grams of fresh soil was filtered through a $2 \mathrm{~mm}$ sieve into an autoclaved Erlenmeyer flask, and $100 \mathrm{ml}$ of $0.85 \%$ sterile sodium chloride solution was added. The sample was sealed, shaken at 180 $\mathrm{r} / \mathrm{min}$ for $30 \mathrm{~min}$ at $25^{\circ} \mathrm{C}$, and statically incubated for $2 \mathrm{~min}$. Then $4 \mathrm{ml}$ of supernatant was drawn to a constant volume of $40 \mathrm{ml}$ ( $0.85 \%$ sodium chloride); $4 \mathrm{ml}$ of a constant volume of $40 \mathrm{ml}(0.85 \%$ sodium chloride) was drawn again. The absorbance was measured at $590 \mathrm{~nm}(0.13 \pm 0.02)$ and $150 \mu \mathrm{L}$ of the solution was absorbed. The plate was incubated at $25^{\circ} \mathrm{C}$, and the absorbance of the ecological plate was measured once every $12 \mathrm{~h}$, continuously for $10 \mathrm{~d}$ (Classen et al., 2003; Liao et al., 2013; Jin et al., 2014).

\section{Statistical analysis}

AWCD was used to describe the soil microbial metabolic activity. The calculation formula is as follows:

$$
A W C D \square \sum\left(C_{i}-R\right) / 31
$$

In the formula, $C_{i}$ is the absorbance value of the hole with a carbon source, $R$ is the absorbance value of the control hole (the control is empty), and $\mathrm{n}$ is the number of carbon sources (31 $\times 3$ repetitions) (Velasco et al., 2009). If $C_{i}-R \leq 0$, then the whole value is recorded as 0 (Kong et al., 2008).

The 96-hour cultivation data were used to calculate the functional diversity of the soil microbial communities. The calculation formula is as follows:

Shannon-Wiener diversity index: $H \square \mathrm{P}_{\mathrm{i}} 1$ n $\mathrm{P}_{\mathrm{i}}$ (Kong et al., 2008)

Simpson diversity index: $D \square^{1-\sum\left(P_{i}\right)^{2}}$ (Kong et al., 2008) 
McIntosh diversity index: $U \square \sqrt{\sum^{\sum n_{i}^{2}}}$ (Xie et al., 2011)

In the formula, $P i$ is the ratio of the relative absorbance value of the $i^{\text {th }}$ to the sum of the relative absorbance values of all.

Data analysis was performed with Excel, SPSS 20.0, and R. SPSS was used for one-way ANOVA analyses with the detection level set at 0.05. Heatmap, Principal Component Analysis (PCA), and redundancy analysis (RDA) were performed with R (Vegan package).

\section{List Of Abbreviations}

BD: Betula dahurica;

LG: Larix gmelinii;

LGBD: Larix gmelinii and Betula dahurica mixed;

AWCD: Average well colour development;

CCA: Canonical correspondence analysis;

SOC: soil organic carbon;

TN: total Nitrogen;

$\mathrm{CN}: \mathrm{C} / \mathrm{N}$;

\section{Declarations}

Ethics approval and consent to participate

The study did not violate ethics, and all participants agreed to publish the paper.

\section{Consent for publication}

Not applicable.

\section{Availability of data and materials}

The original data is recorded in an Excel named "Data record sheet" and has been attached to this article.

\section{Competing interests}

On behalf of all authors, the corresponding author states that there is no conflict of interest. 


\section{Funding}

The work was funded by National Natural Sciences Foundation of China (32011530425), Natural Sciences Foundation of Heilongjiang Province (LH2020C088), Outstanding Youth Foundation of Heilongjiang University (JCL202006) and supported by the State Forestry and Grassland Administration Program (AS2017).

\section{Authors' contributions}

Sui Xin performed this experiment, analyzed the data and wrote this MS, and Li Jiayi performed this experiment and help to wrote this MS; Yin Weiping and Li Guofu helped to collect the soil samples; Ma Weichao helped to analyzed the data; Yang Libin and Mu Liqiang designed this experiment and revised this MS.

\section{Acknowledgements}

We are grateful to Mr. Zhenzhu Zhao, leader of Heilongjiang Zhongyangzhan Black-billed Capercaillie Nature Reserve, for allowing us access to the Nature Reserve; Mr. Zhenzhu Zhao, Fuyuan Chen and Xianda Li for help with sampling, and Mr. Xianda Li for help with sample processing.

\section{References}

Anderson JAH, Hooper MJ, Zak JC, Cox SB (2009) Characterization of the structural and functional diversity of indigenous soil microbial communities in smelter-impacted andnonimpacted soils. Environ Toxicol Chem 28(3):534-540. https://doi.org/10.1897/08-281.1

Bellingham PJ, Walker LR, Wardle DA (2001) Differential facilitation by a nitrogen-fixing shrub during primary succession influences relative performance of canopy tree species. J Ecol 89(5):861-875. https://doi.org/10.1046/j.0022-0477.2001.00604.x

Bossio DA, Scow KM (1995) Impact of carbon and flooding on the metabolic diversity of microbial communities in soils. Appl Environ Microb 61(11):4043-4050. https://doi.org/10.1002/bit.260480315

Buyer JS, Drinkwater LE (1997) Comparison of substrate utilization assay and fatty acid analysis of soil microbial communities. J Microbiol Meth 30(1):1-11. https://doi.org/10.1016/S0167-7012(97)00038-9

Cao HJ, Wang LM, Xu MY, Huang QY, Xie LH, Luo CY, Ni HW (2018) Functional diversity of soil microbial communities of different vegetation types in the new volcanic lava platform of Wudalianchi. Acta Eco Sini 39(21):7927-7937. https://doi.org/10.5846/stxb201808051668

Chodak M, Niklinska M (2010) Effect of texture and tree species on microbial properties of mine soils. Appl Soil Ecol 46:268-275. https://doi.org/10.1016/j.apsoil.2010.08.002 
Classen AT, Boyle SI, Haskins KE, Overby ST, Hart SC (2003) Community-level physiological profiles of bacteria and fungi: plate type and incubation temperature influences on contrasting soils. Fems Microbiol Ecol 44(3):319-328. https://doi.org/10.1016/S0168-6496(03)00068-0

Deng JJ, Zho, YB, Bai X, Luo JY, Zhu WX (2019) Soil microbial functional diversity responses to different revegetation types in baishilazi nature reserve. Pol J Environ Stud 28(5):3675-3686.

https://doi.org/10.15244/pjoes/99100

Ding GC, Wang XH, Yang QF, Lin QX, Huang ZQ (2017) Effects of tree species transition on soil microbial community composition and functions in subtropical China. J Appl Ecol 28(11): 3751-3758. https://doi.org/10.13287/j.1001-9332.201711.039

Eilers KG, Lauber C, Fierer N (2006) Shifts in bacterial community structure associated with inputs of root exudate compounds to soil. FEMS Microbio Ecol 44(3): 319-328.

https://doi.org/10.1016/j.soilbio.2010.02.003

Felipe-Sotelo M, Tauler R, Vives I, Grimalt JO (2008) Assessment of the environmental and physiological processes determining the accumulation of organochlorine compounds in European mountain lake fish through multivariate analysis. Science of the Total Environment 404(1):148-161.

https://doi.org/10.1016/j.scitotenv.2008.06.020

Fierer N, Jackson RB (2006) The diversity and biogeography of soil bacterial communities. Proc Natl Acad Sci U S A 103(3):626-631. https://doi.org/10.1073/pnas.0507535103

Fu Q, Xing YJ, Yan GY, Dong XD, Zhang JH, Wang QG (2019) Response of litter dynamics of boreal forest to long-term nitrogen deposition. Ecol Environ Sci 28(7):1341-1350.

Gao C, Zhang Y, Shi NN, Zheng Y, Chen L, Wubet T (2015) Community assembly of ectomycorrhizal fungi along a subtropical secondary forest succession. New Phytol 205(2):771-785.

https://doi.org/10.1111/nph.13068

Gao F, Jiang H, Cui XY (2015) Soil organic carbon pools and their turn over under two different types of forest in Xiaoxing'an Mountains, Northeast China. J Appl Ecol 26(7):1913-1920.

Gao J, Kang F, Han H (2016) Effect of litter quality on leaf-litter decomposition in the context of homefield advantage and non-additive effects in temperate forests in China. Pol J Environ Stud 25(5):19111920. https://doi.org/10.15244/pjoes/62822

Garland JL (1997) Analysis and interpretation of community-level physiological profiles in microbial ecology. FEMS Microb Ecol 24:289-300. https://doi.org/10.1111/j.1574-6941.1997.tb00446.x

Ge XG, Huang ZL, Cheng RM, Zeng LX, Tan BW (2012) Effects of litter fall and root input on soil physical and chemical properties in Pinus Massoniana plantations in three gorges reservoir area, China. $\mathrm{J}$ Appl Ecol 23(12): 3301-3308. 
Geng SC, Chen ZJ, Zhang JH, Lou X, Yu DD (2013). Soil methane fluxes of three forest types in changbai mountain of northeast China. Chin J Ecol 32(5):1091-1096.

Glanville HC, Hill PW, Maccarone LD, Golyshin P, Murphy DV, Jones DL (2012) Temperature and water controls on vegetation emergence, microbial dynamics, and soil carbon and nitrogen fluxes in a high arctic tundra ecosystem. Funct Ecol 26(6):1366-1380. https://doi.org/10.1111/j.1365-2435.2012.02056.x

Han DX, Wang N, Wang NN, Sun X, Feng FJ (2015). Soil microbial functional diversity of different altitude Pinus Koraiensis forests. Chin J Appl Ecol 26(12): 3649-3656.

Hu C, Fu B, Liu G, Jin T, Guo L (2010). Vegetation patterns influence on soil microbial biomass and functional diversity in a hilly area of the loess plateau, China. J Soils Sediments 10(6):1082-1091. https://doi.org/10.1111/10.1007/s11368-010-0209-3

Hua Z, Zhiyun O, Xiaoke W, Zhiguo F, Tongqian Z, Hong M (2004) Effects of forest restoration patterns on soil microbial communities. Chin J Appl Ecol, 15(11):2019-2024. https://doi.org/10.1016/S09600779(03)00420-X

Huang YY, Qu LY, Qu XC, Du SQ (2012) Soil microbial community characteristics under different vegetation types at the holocene-basalt platform, jingpo lake area, northeast China. Acta Ecol Sini 32(9):2827-2836. https://doi.org/10.5846/stxb201103240371

Illian JB, Prosser JI, Baker KL, Rangel-Castro JI (2009) Functional principal component data analysis: a new method for analysing microbial community fingerprints. J Microbiol Meth 79(1):89-95. https://doi.org/10.1016/j.mimet.2009.08.010

Jiang YS, Xiao J, Luo CL, Li J, Zhang G (2014) The Microbial Community of Three Mountains Pingding, Changbai and Saihanwula Based on the Analysis of Phospholipid Fatty Acids(PLFAs). Ecolo Environ Sci 23(8):1272-1279.

Jin Z, Ji FY, Xu X, Xu XY, Chen QK, Li Q (2014) Microbial and metabolic characterization of a denitrifying phosphorus-uptake/side stream phosphorus removal system for treating domestic sewage. Biodegradation 25(6):777-786. https://doi.org/10.1007/s10532-014-9698-x

Kenarova A, Radeva G, Traykov I, Boteva S (2014) Community level physiological profiles of bacterial communities inhabiting uranium mining impacted sites. Ecotox Environl Safe 100:226-232. https://doi.org/10.1016/j.ecoenv.2013.11.012

Kennedy N, Brodie E, Connolly J, Clipson N (2005) Impact of lime, nitrogen and plant species on fungal community structure in grassland microcosms. Environ Microbiol 7(6):780-788. https://doi.org/10.1111/j.1462-2920.2004.00638.x

Kim JW, Rehmann L, Ray MB (2017) Development of microalgal bioassay based on the community level physiological profiling (clpp). Algal Res 25:47-53. https://doi.org/10.1016/j.algal.2017.04.037 
Kong WD, Zhu YG, Fu BJ, Han XZ, Zhang L, He JZ (2008) Effect of long-term application of chemical fertilizers on microbial biomass and functional diversity of a black soil. Pedosphere 18(6):801-808. https://doi.org/10.1016/S1002-0160(08)60076-4

Liao M, Xie XM, Peng Y, Chai JJ, Na C (2013) Characteristics of soil microbial community functional and structure diversity with coverage of Solidago Canadensis L. J Central South University 20(3):749-756. https://doi.org/10.1007/s11771-013-1544-5

Magdalena F, Oszust K, Lipiec J (2012) Community level physiological profiles (CLPP), characterization and microbial activity of soil amended with dairy sewage sludge. Sensors 12:3253-3268. https://doi.org/10.3390/s120303253

Miyake H, Maeda Y, Ishikawa T, Tanaka A (2016) Calorimetric studies of the growth of anaerobic microbes. J Biosci Bioeng 122(3):364-369. https://doi.org/10.1016/j.jbiosc.2016.02.006

Sarah R, Sattin CC, Cleveland (2010) Functional shifts in unvegetated, perhumid, recently-deglaciated soils do not correlate with shifts in soil bacterial community composition. J Microb 47(6):673-681. https://doi.org/10.1007/s12275-009-0194-7

Sariyildiz T, Anderson JM (2003) Interactions between litter quality, decomposition and soil fertility: a laboratory study. Soil Biol Biochem 35(3):391-399. https://doi.org/10.1016/S0038-0717(02)00290-0

Stéphane B, Frédéric MG, Balandier P (2008) Influence of tree species on understory vegetation diversity and mechanisms involved-a critical review for temperate and boreal forests. Forest Ecol Manag, 254(1):1-15. https://doi.org/10.1016/j.foreco.2007.09.038

Sui X, Zhang RT, Yang LB, Xu N, Chai CR, Wang JF (2016) Effect of simulation nitrogen depositions on bacterial diversity of Deyeuxia Angustifolia in wetland of Sanjiang Plain. Pratacultural Science 33(4):589598.

Sui X, Zhang RT, Yang LB, Xu N, Zhong HX, Wang JF, Ni HW (2016) Functional diversity of soil bacterial communities in different types of Calamagrostis angustifolia wetlands in Sanjiang Plain. Res Environ Sci 29(10):1479-1486.

Tripathi G, Deora R, Singh G (2013) The influence of litter quality and micro-habitat on litter decomposition and soil properties in a silvopasture system. Acta Oecol, 50:40-50. https://doi.org/10.1016/j.actao.2013.01.013

Ushio M, Kitayama K, Balser TC (2010) Tree species effects on soil enzyme activities through effects on soil physicochemical and microbial properties in a tropical montane forest on Mt. Kinabalu, Borneo. Pedobiologia 53(4):230-233. https://doi.org/10.1016/j.pedobi.2009.12.003

Ushio M, Kitayama, K, Balser TC (2010) Tree species-mediated spatial patchiness of the composition of microbial community and physicochemical properties in the topsoils of a tropical montane forest. Soil 
Biol Biochem 42(9):1588-1595. https://doi.org/10.1016/j.soilbio.2010.05.035

Velasco GV, Probanza A, Ero FJG, Trevi OAC, Moreno JM, Garcia, JAL (2009) Effect of fire and retardant on soil microbial activity and functional diversity in a mediterranean pasture. Geoderma 153(1-2):185193. https://doi.org/10.1016/j.geoderma.2009.08.005

Waid JS (1999) Does soil biodiversity depend upon metabiotic activity and influences? Appl Soil Ecol 13(2):151-158. https://doi.org/10.1016/S0929-1393(99)00030-X

Wu ZY, Lin WX, Chen ZF, Fang CX, Zhang ZX, Wu LK, Zhou MM, Shen LH (2013) Characteristics of soil microbial communities of different vegetation types in Wuyishan National Nature Reserve. Chin J Appl Ecol 24(8):2301-2309.

Xi JY, Hu HY, Jiang J, Qian Y (2005) Metabolic characteristics of the microbial community in the biological filter tower. Environ Sci 26(4):167-172.

Xie XM, Liao Min, Ma AL, Zhang HJ (2011) Effects of contamination of single and combined cadmium and mercury on the soil microbial community structural diversity and functional diversity. Chin $\mathrm{J}$ Geochem, 30:366-374. https://doi.org/10.1007/s11631-011-0521-7

Zhang X, Xuan Z, Zhao M (2012) Functional diversity changes of microbial communities along a soil aquifer for reclaimed water recharge. FEMS Microb Ecol 80(1):9-18. https://doi.org/10.1111/j.15746941.2011.01263.x

Yang YG, Paterson E, Campbell C (2002) Application of Biolog method to distinguish microbial characteristics between urban soil and rural soil. Acta Pedologica Sinica 39(4):582-589.

Yin WP, Li GF, Zhao ZZ, Chen FY, Qiu GL, Liu WS (2019) Species diversity and distribution of orchids in heilongjiang zhongyangzhan black-billed capercaillie national nature reserve. J Qiqihar Uni 35(5):52-65.

Yoshimura C, Gessner MO, Furumai TH (2008) Chemical properties, microbial respiration, and decomposition of coarse and fine particulate organic matter. J the N AM Benthol Soc 27(3):664-673. https://doi.org/10.1899/07-106.1

Yoshitake S, Fujiyoshi M, Watanabe K, Takehiro M (2013) Successional changes in the soil microbial community along a vegetation development sequence in a subalpine volcanic desert on mount fuji, Japan. Plant \& Soil 364(1-2): 261-272. https://doi.org/10.1007/s11104-012-1348-7

Zhang QR, Zhou QX, Ren LP, Zhu YG, \& Sun SL (2006) Ecological effects of crude oil residues on the functional diversity of soil microorganisms in three weed rhizospheres. J Environ Sci 18(6):1101-1106. https://doi.org/10.1016/S1001-0742(06)60046-6

Zheng H, Ouyang ZY, Fang ZG, Zhao TQ (2004) Application of Biolog in functional diversity of soil microbial community. Acta Pedolog Sin 1(3):456-461. 
Figures

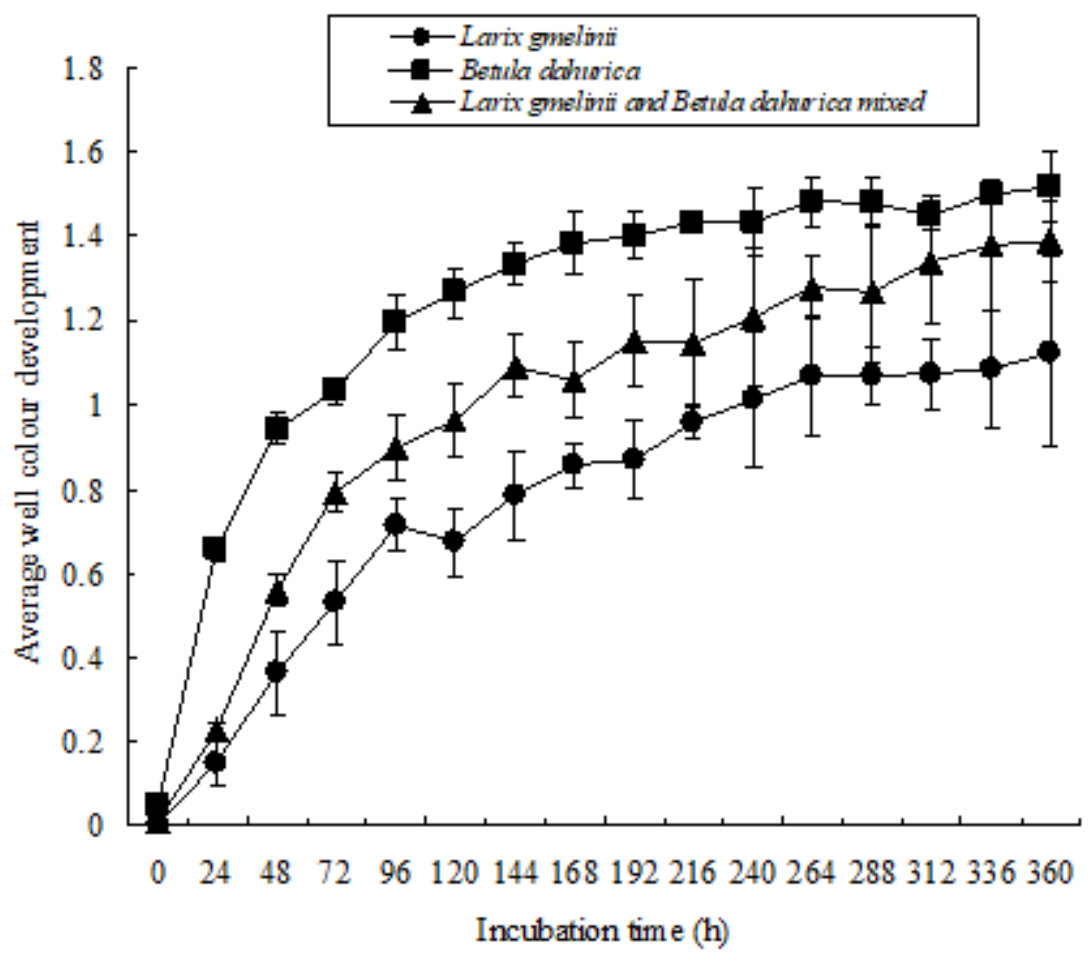

Figure 1

Average well colour development (AWCD) of the soil community for 3 different vegetation types with incubation time.

Image not available with this version

Figure 2

Figure not available in this version. 

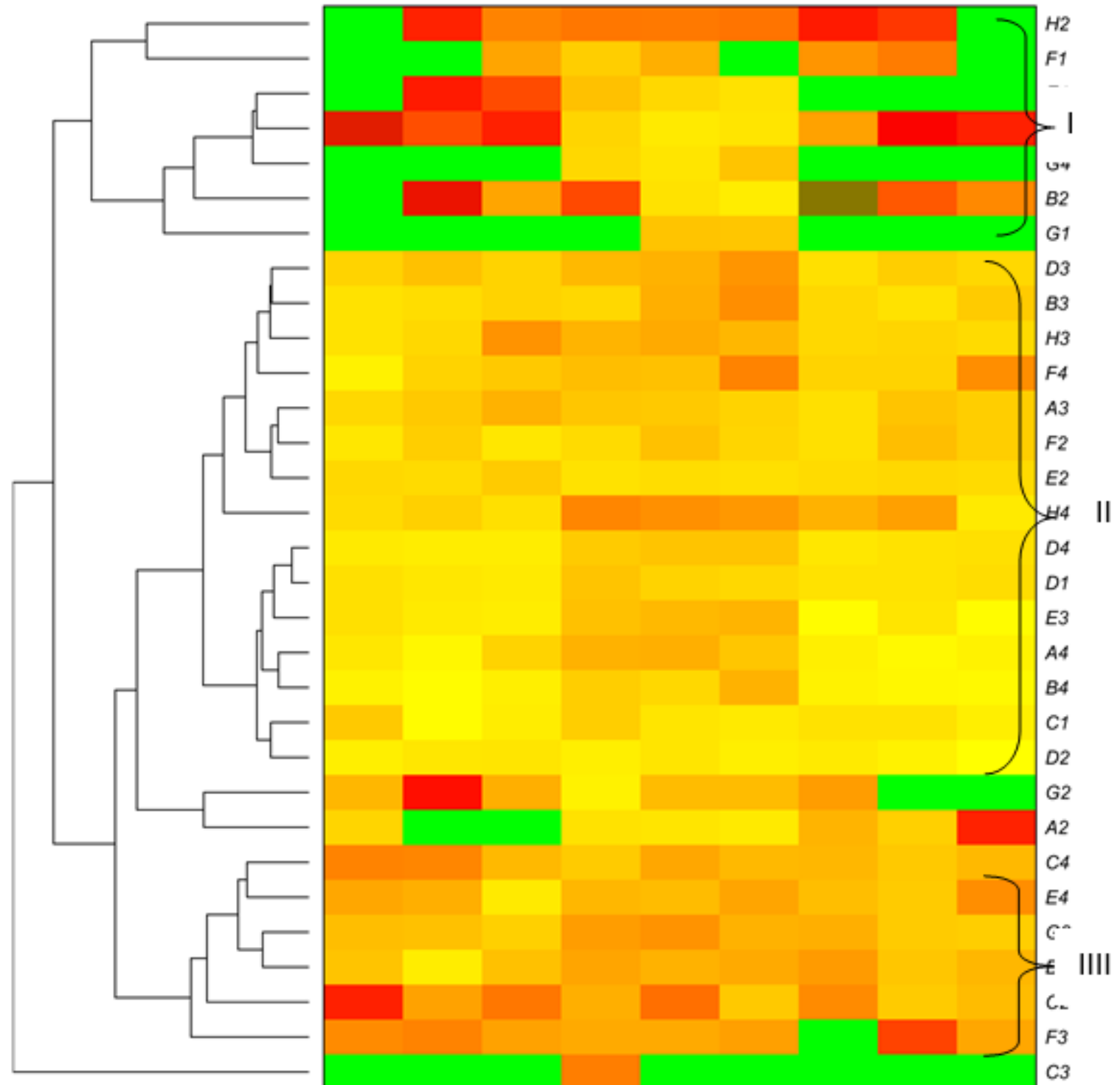

II

D4

D1

E3

A4

B4

C1
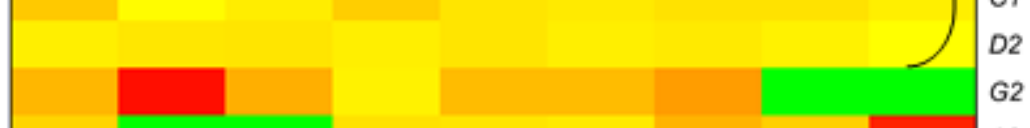

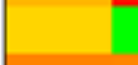

G2

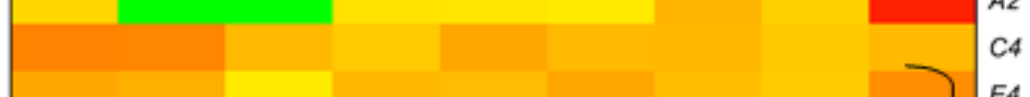

E4

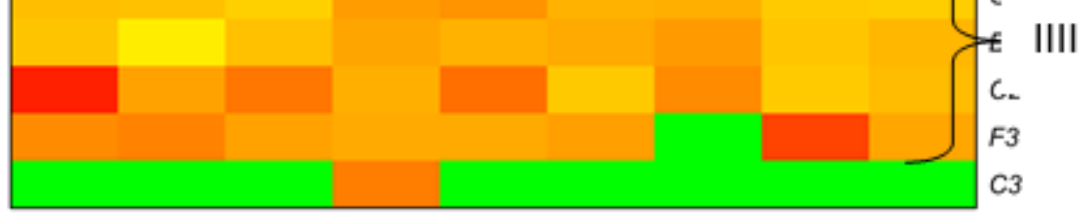

BD1 BD2 BD3 LG1 LG2 LG3 LGBD1 LGBD2 LGBD3

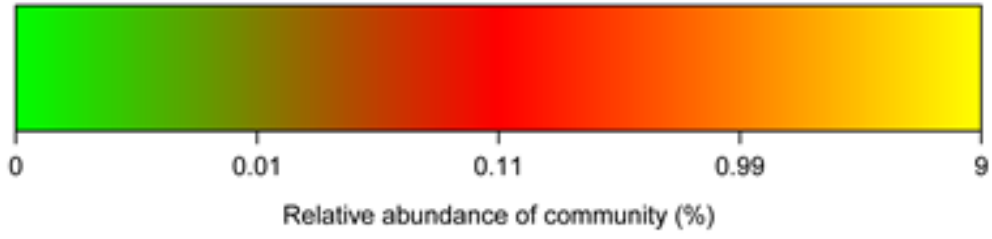

\section{Figure 3}

Heatmap and hierarchical cluster analysis based on the AWCD of $72 \mathrm{~h}$ for the soil microbial communities with different revegetation types. Note: The samples are grouped based on the similarity to each other, and the clustering results are arranged horizontally according to the clustering results. In the figure, red represents the higher AWCD in the corresponding sample, and green represents the lower AWCD. LG: Larix gmelinii; BD: Betula dahurica; and LGBD: mixed Larix gmelinii and Betula dahurica. 


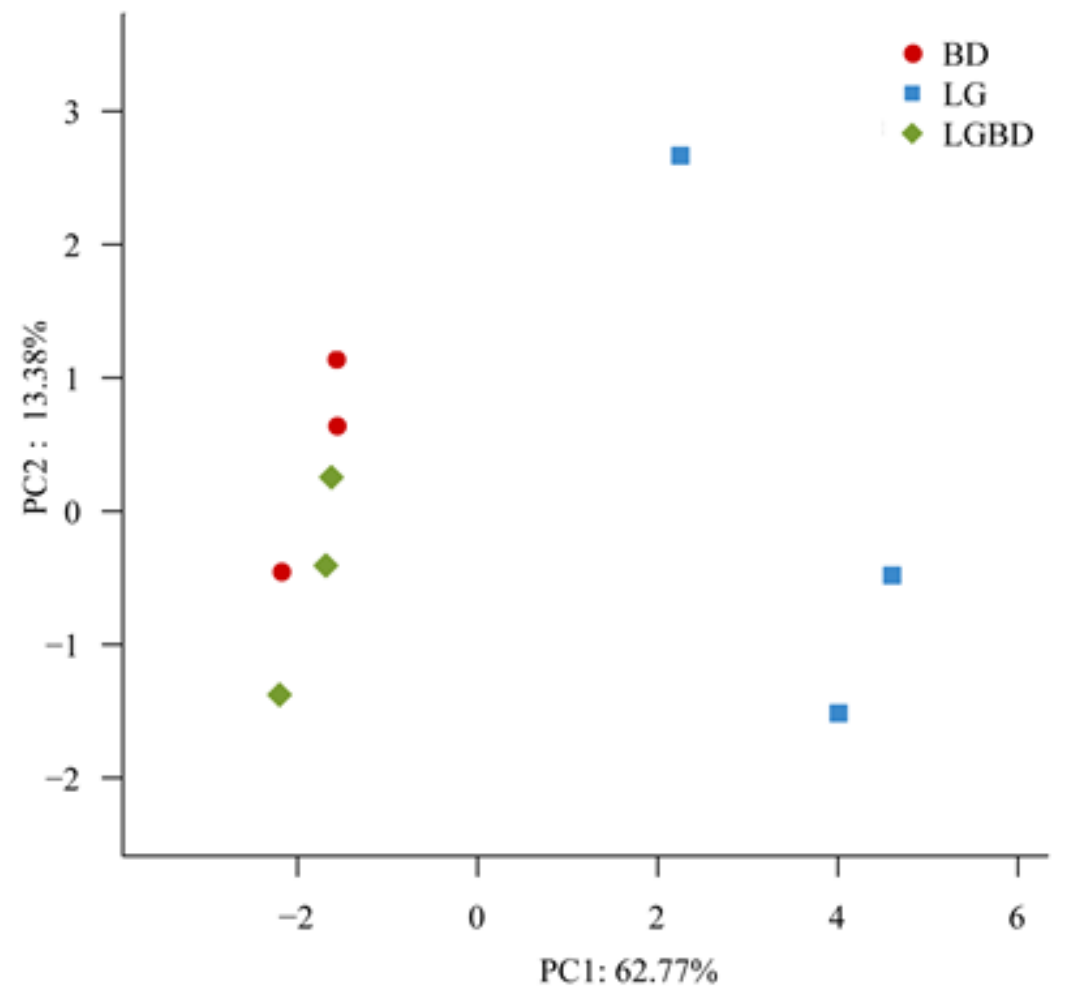

\section{Figure 4}

Principal component analysis plot of soil carbon source metabolism of the different microbial communities. Note: BD: Betula dahurica; LG: Larix gmelinii; and LGBD: mixed Larix gmelinii and Betula dahurica. 


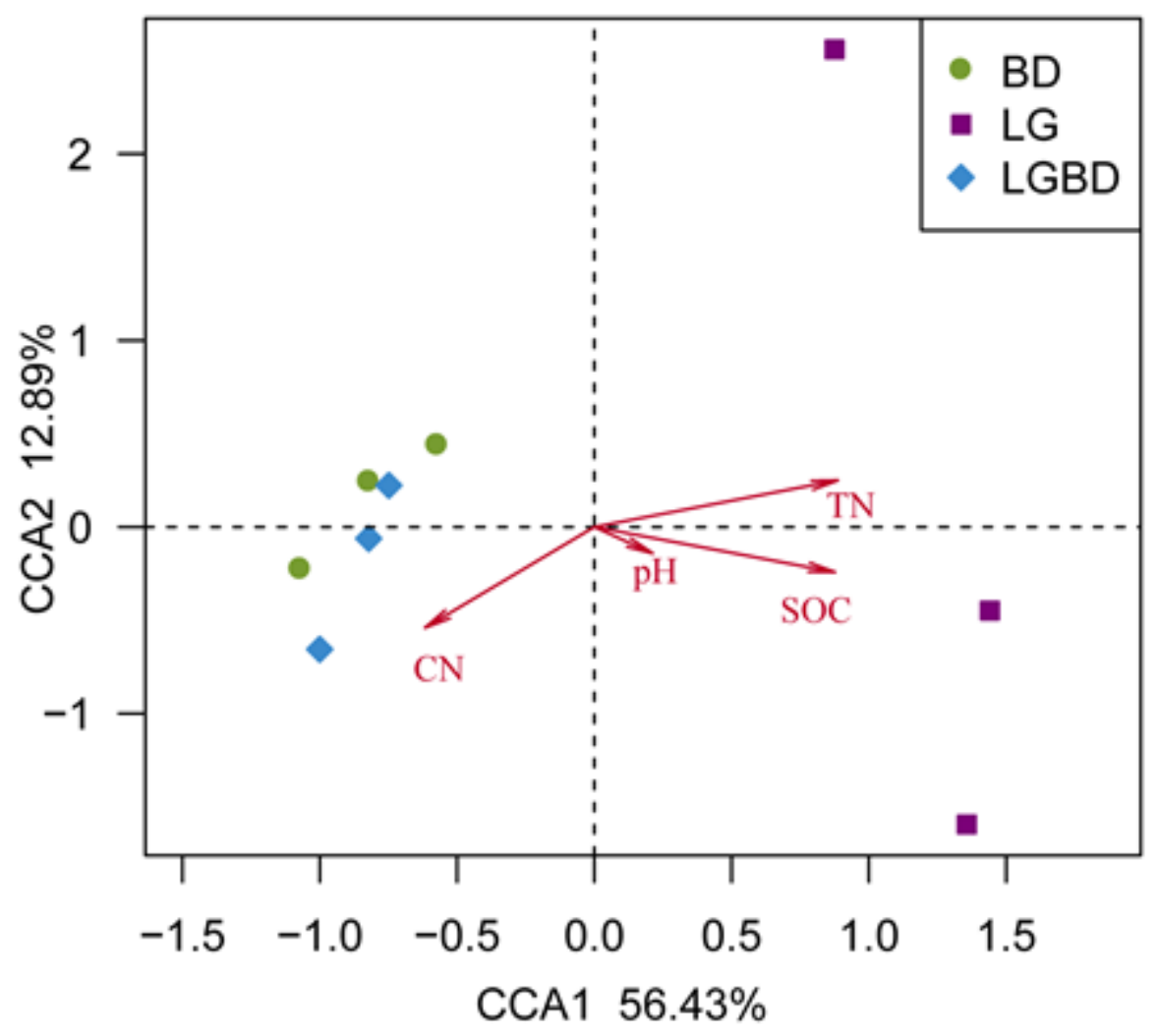

Figure 5

Canonical correspondence analysis (CCA) ordination plots of the functional microbial community structure under different revegetation types. Note: SOC, soil organic carbon; TN, total N; CN, C/N. BD: Betula dahurica; LG: Larix gmelinii; and LGBD: mixed Larix gmelinii and Betula dahurica. 


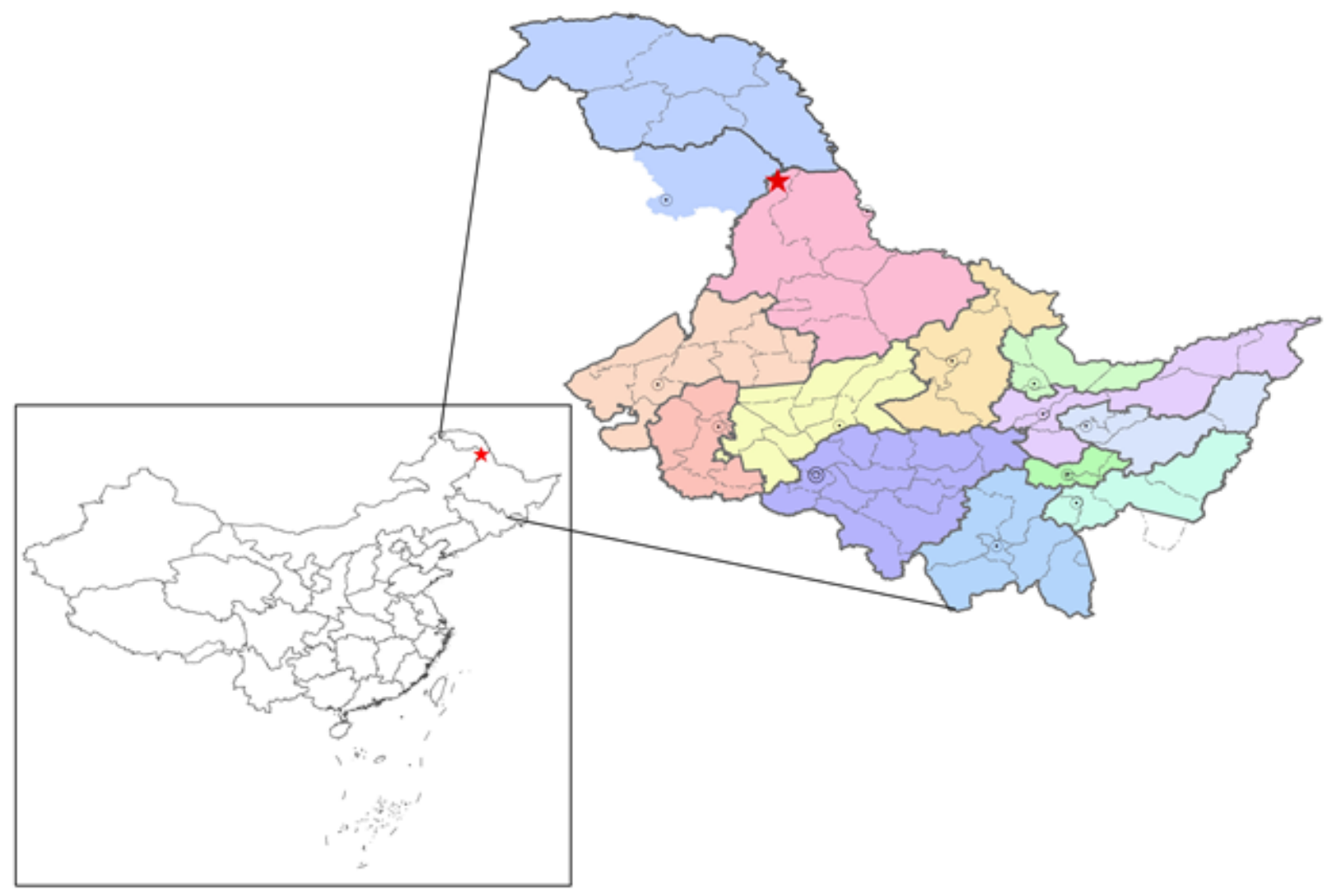

Figure 6

Location of the study area. Note: The designations employed and the presentation of the material on this map do not imply the expression of any opinion whatsoever on the part of Research Square concerning the legal status of any country, territory, city or area or of its authorities, or concerning the delimitation of its frontiers or boundaries. This map has been provided by the authors. 